\title{
Facilitating co-production in public services: Empirical evidence from a co-design experience with family caregivers living in a remote and rural area
}

\author{
Authors: Eleonora Gheduzzi, Niccolò Morelli, Guendalina Graffigna, Cristina Masella \\ This paper was published in November 2020 on Health Services Management Research (ISSN: \\ 0951-4848). The link at the publication is: https://doi.org/10.1177/0951484820971452
}

\begin{abstract}
The involvement of vulnerable actors in co-production activities is a debated topic in the current public service literature. While vulnerable actors should have the same opportunities to be involved as other actors, they may not have the needed competences, skills and attitudes to contribute to this process.

This paper is part of a broader project on family caregivers' engagement in remote and rural areas. In particular, it investigates how to facilitate co-production by looking at four co-design workshops with family caregivers, representatives of a local home care agency and researchers. The transcripts of the workshops were coded using NVivo, and the data were analysed based on the existing theory about co-production.

Two main findings were identified from the analysis. First, the adoption of co-production by vulnerable actors may occur in conjunction with other forms of engagement. Second, the interactions among facilitators and providers play a crucial role in encouraging the adoption of co-production. We identified at least two strategies that may help facilitators and providers achieve that goal. However, there is a need for an in-depth understanding of how facilitators and providers should interact to enhance implementation of co-production.
\end{abstract}

Keywords: co-production, health, caregiver, co-design, facilitator, patient engagement 


\section{Introduction}

Involving users in the prioritisation, design, implementation and assessment of public services has garnered a significant amount of attention in the last 20 years. ${ }^{1,2}$ Interest in this approach has grown due to the increasing divergence of expectations and needs between service users and public service providers. $^{3}$

Users would like to have an active role in defining public services by expressing their preferences and opinions. Especially for specific topics, such as disability, they claim to have the experiential knowledge that enables them to understand how public decisions affect their lives. Their exclusion in the definition and provision of public services increases their dissatisfaction and mistrust in the public sector: 'nothing about us without us' (Loeffler and Bovaird, ${ }^{4}$ p. 405) Public providers are looking for tailored service solutions that effectively meet the expectations ${ }^{5}$ of users, especially those that are marginalised. ${ }^{6}$ Additionally, providers have been forced to reduce public expenditures after the recent crisis (i.e. financial cutbacks of 1970s and 1980s, and the global financial crisis in 2007 and 2008) (2,7 $^{2}$ and collaborate with actors from different organisations. ${ }^{8}$

Within this scenario, co-production has emerged as one possible solution to meet the needs of both service users and providers. It differs from other types of citizen engagement in that it facilitates an equal partnership between users and service providers in defining and implementing public services ${ }^{9}$ : 'If you want to walk fast, travel alone: if you want to walk far, travel together'(Löffler et al. ${ }^{10}$ p. 2).

Co-production was first defined by Ostrom as 'a process through which inputs from individuals who are not "in" the same organization are transformed into goods and services'(Ostrom, ${ }^{11}$ p.1073). It has positive effects on providers and users. The involvement of users increases the providers' knowledge about the users' needs, enabling them to improve the effectiveness, efficiency and innovativeness of the services. ${ }^{12,13}$ Co-production enables users to express their needs and expectations and influence the definition and implementation of public services, reducing the divergence and mistrust they have towards public providers. ${ }^{14}$ In particular, co-production offers a valuable opportunity for vulnerable groups of actors to be heard. ${ }^{11,15}$

However, a growing number of studies are debating the adoption of co-production with marginalised, disadvantaged and fragile users. ${ }^{16,17}$ Although co-production promotes the involvement of all types of people, regardless of their personal characteristics, ${ }^{12}$ several studies have reported that some people are more inclined towards engaging in co-productive activities. ${ }^{18}$ The actors participating in coproductive activities are usually women ${ }^{19}$ with a medium-high level of education, good 'dialogical interaction'(Ballantyne and Richard, ${ }^{20}$ p. 225-226), a significant amount of free time ${ }^{12}$ and good health and well-being. ${ }^{21}$ These findings suggest that vulnerable individuals with a low level of 
education and well-being that are living in communities that are difficult to reach may be excluded from co-productive activities. This inhibits the possibility of vulnerable actors collaborating as equal partners with the other stakeholders involved ${ }^{22}$ and it threatens the democracy that characterises the co-production process. ${ }^{23}$ To promote inclusion and address inequality, it is important to investigate the current debate on the engagement of fragile, disadvantaged and marginalised actors in coproductive activities. ${ }^{1,12}$ In particular, scholars should investigate the factors that facilitate or limit the management of co-production with vulnerable actors to ensure its successful implementation and prevent possible pitfalls that may impede the process. ${ }^{24,25}$

Discussing and exploiting this debate has two benefits. First, it supports and encourages service providers in adopting co-production even with vulnerable actors. Second, it allows users that are typically excluded from the public debate to influence the service providers' decisions by including their needs and expectations in the existing service systems.

\section{Study objective}

To investigate how to involve vulnerable actors ${ }^{26}$ in co-production activities, ${ }^{14}$ this paper focuses on a specific example of public service co-production with poor, isolated, vulnerable people that are defenceless in the face of risk, shock or stress. ${ }^{27}$ In particular, we chose to investigate the involvement of family caregivers of elderly people whose access to the local healthcare system is usually weak and inconsistent, especially in remote and rural areas. ${ }^{28}$

This research is part of a broader project on the co-production of new public services with and for family caregivers. Since the process of co-production was thought-provoking, substantial and complex, it is suitable for a broad reflection on the management of the process by investigating: (i) the conductive methods that facilitated its adoption, (ii) the pitfalls that limited its fair and successful implementation and (iii) the interactions that occurred during the process. Within this scenario, the main contribution of this paper is that it studied the conductive methods that encouraged an equal and constructive exchange among actors in terms of defining new public services. Thus, we addressed the following research question:

$R Q:$ How can co-production of new public services be facilitated by involving family caregivers of elderly people living in a remote and rural area?

This article is organised as follows. First, it presents a review of the relevant literature that has investigated the co-production concept and its adoption. Second, it explains the methodology used to 
conduct the current research and collect the data. Third, it presents the research results and discusses them in light of the existing literature. The fourth and last section presents the implications of the findings, highlighting the limitations of the research.

\section{Conceptual background}

\section{Defining co-production}

Although co-production was first introduced in the 1970s, it has generated new scholarly interest in the public sector in the last twenty years, ${ }^{1}$ resulting in a significant number of academic and nonacademic papers, conferences and programs about it. ${ }^{2}$ Several scholars in a variety of disciplines have investigated it using different methods (single, multiple and longitudinal case studies, surveys, experiments). ${ }^{7}$ However, this growing interest in co-production has not provided any clarity about this concept. ${ }^{19,29}$ Scholars have disagreed on several aspects of co-production (e.g. the voluntariness, the roles of users and professionals, the phases of involvement in the service life cycle), ${ }^{17}$ making it impossible to recognise a unique and universally valid definition. ${ }^{2,30}$ To clarify this complex scenario, recent publications have studied and summarised this conceptual confusion by reflecting on both the 'co-' and the 'production' parts of the concept (e.g. Nabatchi et al., 2017; Brandsen \& Honingh, 2015; Voorberg et al., 2015; Bovaird, 2007). 2,7,16,31

The 'co-' part of this concept defines the groups of actors that collaborate in co-production activities. ${ }^{32,33}$ Since co-production entails equal collaboration between lay and state actors, ${ }^{2}$ the literature has classified the "co-' part into main two groups.

The first group includes the recipients of the service that do not belong to the service organisation. This group consists of active actors, who have a direct relationship with the providers (e.g. service users), and passive actors, who have an indirect relationship with the co-production activities (e.g. the community). ${ }^{16,22}$ However, this is not the only way that the lay actors have been classified. Voorberg et al. (2015) defined service recipients using the broader term: citizens; ${ }^{31}$ Nabatchi et al. (2017) described them based on their role in the process: citizens, clients and customers. ${ }^{2}$ According to this last classification, recipients of a public service may be involved because they belong to a specific geographical community (i.e. citizens), have the right to use a service (i.e. clients) and/or have to pay for using the service (i.e. customers). ${ }^{2}$

The second group of actors that is involved in co-productive activities has also been classified in different ways in the literature. ${ }^{34}$ According to Brandsen and Honingh (2015), this group should include all the 'regular producers' of the service providers organisations that may (or may not) have 
a specific knowledge. ${ }^{7}$ In contrast, Nabatchi et al. (2017) preferred to describe this group as the set of actors that are employed on the behalf of the state. ${ }^{2}$ However, the majority of the current literature agreed on broadening the definition of this group by including several actors, such as public authorities (e.g. municipalities), ${ }^{35}$ managers and employees of public service organisations ${ }^{36}$ or private firms ${ }^{37}$, experts ${ }^{22}$ and non-government organisations (NGOs) ${ }^{38}$.

The 'production' part of the co-production concept refers to the phase of involvement ${ }^{2}$ of the users along the service life cycle and the type of collaboration that is established. ${ }^{33,39}$ Previous studies have identified four possible phases of user involvement:

- Co-commissioning, during which the actors define the outcomes they are willing to achieve;

- Co-design, during which the actors revise or design the services to achieve the outcome;

- Co-delivery, in which the actors take action to deliver the service outcome;

- Co-assessment, which aims to analyse what worked and why. ${ }^{12,40}$

Involving users in more than one phase increases the number of interactions with providers, which results in more effective and efficient service outcomes. ${ }^{4}$

However, other studies have suggested that co-production occurs at the point of delivery of the service during the interaction between service users and providers. According to this view, co-production is involuntary because it inevitably occurs inevitably during the delivery of public services (i.e. the 'moment of truth') (Osborne et al. ${ }^{22}$ p. 641). Brandsen and Honingh (2018) further investigated this view by defining co-production as the type of involvement of service users that only occurs during the last phases of the service life cycle. ${ }^{41}$

These two different views arose from one of the most discussed elements of the definition of coproduction, namely its compulsoriness. ${ }^{7}$ While the first set of studies described co-production as the users' voluntary choice of being involved in one or more phases of the service life cycle, the second set of studies considered co-production as an 'inalienable core component of service delivery'(Osborne et al. ${ }^{22}$ p. 641) that occurs in the last phases of the service life cycle (e.g. at the point of delivery). ${ }^{41}$

\section{From public engagement to co-production}

Although the existing literature does not provide a unique definition of co-production, recent studies have started to reveal relevant insights about this concept by investigating the actors involved, its antecedents, its positive and negatives effects and the process itself. ${ }^{1,42}$ To investigate how co- 
production occurs, scholars have often started by distinguishing it from other types of citizen engagement. In particular, co-production differs because citizens are not only recipients of a service (or a policy), they are also creators of the service. ${ }^{32,43}$ The rest of this section highlights two examples that describe co-production as a further step of public engagement. ${ }^{32}$

First, Mangai and de Vries (2018) defined co-production as the penultimate level of Stewart's continuum of engagement. ${ }^{44}$ They illustrated this continuum using six levels of engagement: information, consultation, deliberation, partnerships, participatory governance and delegation, in which citizens have the right to take decisions by (and for) themselves. These levels are cumulative because each level of the continuum includes all the previous levels. ${ }^{45}$ For instance, co-production, implies information, consultation, deliberation and partnership. ${ }^{44}$

Second, Loeffler and Martin (2015) proposed a new framework of public engagement by referring to the traditional 'ladder of citizen participation' suggested by Arnstein (1969). ${ }^{4,46}$ This new framework includes four levels of user contributions. Each level describes a specific type of collaboration between users and providers: information, consultation, participation in public decision-making and co-production of public services and outcomes. ${ }^{47}$ Unlike Mangai and de Vires's (2018) framework, ${ }^{44}$ the four levels are mutually exclusive: service providers can choose one of these types of user contributions based on the aim of the collaboration. For instance, consultation includes citizen juries during which citizens are asked to prioritise public spending or to unveil policy issues. ${ }^{47}$

\section{Facilitating co-production}

There are several examples of studies in the existing literature that investigated the drivers for facilitating the adoption of co-production. Sicilia at al. (2019) recently organised these findings though a systematic literature review. ${ }^{25}$ They highlighted that few empirical studies have investigated how to design the co-production process successfully. ${ }^{25}$ Nevertheless, there are some relevant suggestions for designing the co-production process. First, any conflicts or misunderstanding within the group should be solved ${ }^{48}$ because the participants' experience can influence the outcome of the co-production process. ${ }^{25,49}$ Second, it is important to increase the team's sense of identity and its cohesiveness ${ }^{48}$ by promoting equal collaboration among the actors. ${ }^{50}$ Third, participants should be involved through the service life cycle by increasing the frequency of their interactions. ${ }^{25,50}$ However, these suggestions do not adequately explain how to design the co-production process successfully; they only provide very broad and high-level guidelines. Moreover, they seem to be 'one-size-fits-all' suggestions that cannot be applied to co-production, which is always context specific. ${ }^{51}$

To enrich these results, we reviewed the co-design literature. Although the concept of co-design is defined differently (i.e. 'the creativity of designers and people not trained in design working together 
in the design development process', Sanders and Stappers ${ }^{52}$ p. 2), the following findings may help unveil the complexity of designing a co-production process and provide evidence to support the purpose of the current study.

Dietrich et al. (2017) studied how to conduct co-design workshops with vulnerable actors by comparing that process with the conventional process. ${ }^{53}$ At the beginning of the co-design process, the facilitators cannot limit their effort in 'setting the scene'. The presence of vulnerable actors requires facilitators to carefully explain the requirements and aims of the process by providing practical examples and asking thought-provoking questions. This phase is crucial for increasing the team's sense of identity and ensuring that vulnerable actors are knowledgeable about the research aim. Similarly, during the process, the facilitators cannot simply adopt a passive role; they should guide vulnerable users, step-by-step. In particular, they should use two steps to organise the co-design process. First, they should encourage the involvement of vulnerable actors by organising 'ice-breaker' activities. Once the participants start to feel confident within the group and about the topic being discussed, the facilitators can encourage the group discussion for co-designing new service ideas. ${ }^{53}$

Pederson (2020) reflected on the role of the facilitator for encouraging a successful co-design process. ${ }^{54}$ She identified three recurrent phases that characterise the entire process. In the first stage (i.e. staging), the facilitator frames the stage by involving actors in the process. In the second phase (i.e. negotiation), the facilitator encourages the participants to discuss the issues, thereby fostering negotiation. The results of the negotiation process define the last phase (i.e. (re)framing) in which the facilitator (or participants) identifies a new issue to discuss, setting the stage for a new negotiation. These three phases are iterative and are encouraged and guided by the facilitator throughout the codesign process. ${ }^{54}$

Finally, Meroni et al. (2018) prosed a Collaborative Design Framework consisting of four iterative and continuous stages that occur during the co-design process and are guided by facilitators. ${ }^{55}$ In the first stage (i.e. discovering and exploring options), the aim of the collaboration is to unveil the needs and personal experiences of the participants by increasing their engagement. In the second stage (i.e. imagining and considering options beyond the world as it is), facilitators encourage the participants to think about options that go beyond the current scenario by provoking them with different scenarios. In the third stage (i.e. expanding and consolidating options), the participants are asked to enrich the suggested ideas by reflecting on their feasibility and implementation. In the last phase (i.e. creating, envisioning and developing opinions), the facilitators encourage the participants to develop, in detail, the co-designed service by provoking the processes and facilitating open discussion. ${ }^{55}$ 


\section{Method}

An explanatory single holistic case study approach was used in the present study, since it best fits the "how" of the research question ${ }^{56}$ and its study of a phenomenon ${ }^{57}$ in light of existing theories. Since we investigated the adoption of co-production in light of a well-formulated theory, the adoption of a single case is sufficient for testing the existing theory, thereby confirming, challenging or extending it. ${ }^{56}$ This research method is relevant because it uses qualitative data to investigate a contemporary and often-discussed phenomenon in a real-life context, ${ }^{58}$ enhancing the ability of academics to contribute to the understanding of co-production's adoption with vulnerable actors.

\section{Case and context description}

To investigate the research question, we looked for a case that adopted co-production with vulnerable actors that is transparently observable. Based on this premise, we selected a longitudinal project launched to co-produce (i.e. co-design, co-delivery and co-assessment) a new social and community service for family caregivers of elderly citizens in a remote and rural valley in northern Italy (i.e. Vallecamonica). This project was funded by Fondazione Cariplo and conducted with the Università Cattolica del Sacro Cuore, a local home care agency (ATSP), Politecnico di Milano University and the Need Institute. Four local assisted living facilities and the home care agency for safeguarding people's health also collaborated informally on the project. ${ }^{59}$

This project was selected for three main reasons. First, it investigates the co-production of public services involving family caregivers belonging to a vulnerable, remote and rural community. Second, it can be used to explore and extend the existing theory about the implementation of co-production. ${ }^{60}$ Third, the process of interaction between users and providers during co-creative activities can be 'transparently observable'. 61 (pp. 277)

In this context, the users are family caregivers of elders that live at home and have received home care services with the home care agency or the local assisted living facilities. Caregivers are very vulnerable; caring for elders is challenging and demanding work ${ }^{62}$ that has a negative effect on their health and well-being. ${ }^{63}$ The vulnerability of the project's target group (66 family caregivers) results in a medium-high level of burden (45\%) and a high number of hours of caregiving each week (77.8 hours/week). As shown in Table 1, most of the caregivers are women (78.9\%), unemployed or retired (unemployed: 32.3\%; retired: $40 \%$ ), around 60 years of age, with a medium-low education level (nearly $60 \%$ have not completed high school).

Table 1 Characteristics of family caregivers (data refer to the entire target group of 66 caregivers)

\begin{tabular}{c|c|c|c|c|c|c}
$\begin{array}{c}\text { Number of } \\
\text { participants }\end{array}$ & Age & Sex & Education level & Working status & Burden Level & $\begin{array}{c}\text { Hours of } \\
\text { caregiving }\end{array}$ \\
\hline 26 caregivers & 60 & Male: $21.2 \%$ & Diploma: $4.6 \%$ & $\begin{array}{c}\text { Employed: } \\
27.7 \%\end{array}$ & $\begin{array}{c}\text { Time-Dependence } \\
\text { Burden: } 80 \%\end{array}$ & $77.8 \mathrm{~h} /$ week
\end{tabular}




\begin{tabular}{|c|c|c|c|c|c|c|}
\hline $\begin{array}{c}\text { (out of } 66 \\
\text { caregivers } \\
\text { involved in the } \\
\text { project) }\end{array}$ & $\begin{array}{c}\text { (max: } 89 \text {; } \min : \\
43)\end{array}$ & Female: $78.9 \%$ & $\begin{array}{c}\text { High School: } \\
36.9 \% \\
\text { Primary School: } \\
58.5 \%\end{array}$ & $\begin{array}{l}\text { Unemployed: } \\
\text { 32.3\% } \\
\text { Retired: } 40 \%\end{array}$ & $\begin{array}{l}\text { Developmental Burden: } \\
60 \% \\
\text { Physical Burden: } 46 \% \\
\text { Social Burden: } 26 \% \\
\text { Emotional Burden: } 14 \%\end{array}$ & $\begin{array}{l}\text { (max: } 168 ; \\
\text { min: } 10)\end{array}$ \\
\hline
\end{tabular}

\section{Data collection}

During the co-production activities that were used to design public services for family caregivers, we gathered data from four workshops. The four assisted living facilities and the home care agency (i.e. ATSP) were in charge of contacting all the patients and inviting their family caregiver to participate in the project. Once the caregivers indicated their availability, a psychologist affiliated with the home care agency invited them to participate in the co-production activities. Since this study aimed to investigate the conductive methods to achieve co-production during workshops, the survey results were only used to interpret and contextualise the findings. Overall, we conducted four co-design workshops over the course of seven months involving 26 family caregivers, two ATSP representatives and five researchers. On average, nine caregivers and three project team members, i.e. two project researchers and one home care agency representative, participated in each of the four workshops.

The caregivers were involved as service users because they would utilise the service. The project team consisted of the ATSP representatives and the project researchers. These two actors contributed differently to the co-production process due to the peculiarities of their competences:

- The ATSP representatives (i.e. providers) have extensive experience in designing and implementing services for elders and other vulnerable actors in the area. Thus, their involvement in the workshops aimed at supporting caregivers in co-designing feasible service solutions by preventing them from creating unattainable expectations.

- The researchers (i.e. facilitators) are knowledgeable about co-production and public involvement. Thus, they were involved to manage the workshops. During the workshops, one researcher facilitated the workshops and the other observed and took notes about the exchanges among the participants.

The facilitators had two main tasks: i) facilitate the group, encouraging equal participation from all the participants, and then summarise and organise the findings; ii) encourage active participation of the family caregivers to ensure a stimulating discussion. ${ }^{64}$ 
The first three workshops were split into two sessions. During the first session, the facilitators asked the caregivers to introduce themselves to the rest of the group by describing their caregiving activities and the challenges related to identifying their needs and expectations. During the second session, the caregivers were asked to prioritise their needs and design possible service interventions. ${ }^{12}$ (For more details about the structure of the workshop, see the information provided in the Appendix).

As proven by the structure of the workshop, the providers were not directly consulted by the facilitators because the project team preferred to prevent any possible power imbalances. ${ }^{65}$ Since the role of the providers may inhibit the caregivers' opinions, the structure of the workshops did not explicitly involve them in the discussion (even if they were free to interrupt and intervene during the workshops).

After the providers collected and organised the services ideas that arose from these three workshops, all the participants were invited to take part in an additional workshop to discuss the results and finalise the new public services. Table 2 provides details about the data sources, specifying the duration, the participants and the objective of each workshop.

Table 2 Data Inventory

\begin{tabular}{|c|c|c|c|}
\hline Data Type & Duration & Participants & Objective \\
\hline \multirow{4}{*}{$\begin{array}{l}\text { Co-design } \\
\text { Workshops }\end{array}$} & 1h $45 \mathrm{~min}$ & $\begin{array}{c}\text { Co-design Workshop 1: } 7 \text { caregivers, } 2 \text { ATSP } \\
\text { representatives and } 3 \text { researchers }\end{array}$ & \multirow{3}{*}{$\begin{array}{l}\text { Co-design Workshops 1, 2, 3: identify the } \\
\text { needs and expectations of the service and } \\
\text { start to co-design possible service solutions }\end{array}$} \\
\hline & $2 \mathrm{~h} 39 \mathrm{~min}$ & $\begin{array}{l}\text { Co-design Workshop 2: } 12 \text { caregivers, } 1 \text { ATSP } \\
\text { representatives and } 3 \text { researchers }\end{array}$ & \\
\hline & $2 \mathrm{~h} 01 \mathrm{~min}$ & $\begin{array}{c}\text { Co-design Workshop 3: } 7 \text { caregivers, } 1 \text { ATSP } \\
\text { representatives and } 1 \text { researcher }\end{array}$ & \\
\hline & $1 \mathrm{~h} 12 \mathrm{~min}$ & $\begin{array}{l}\text { Co-design Workshop 4: } 8 * \text { caregivers, } 1 \text { ATSP } \\
\text { representatives and } 2 \text { researchers } \\
\text { [Overall: } 26 \text { caregivers, } 2 \text { ATSP representatives. } \\
\text { and } 6 \text { researchers] }\end{array}$ & $\begin{array}{l}\text { Co-design Workshop 4: co-design a new } \\
\text { service starting from the results of the } \\
\text { previous three workshops }\end{array}$ \\
\hline
\end{tabular}

Note: *participants that have already taken part in one of the three previous workshops

The family caregivers were informed about the purpose and phases of the research study, highlighting the steps of the data collection process. Participation in the surveys and workshops required family caregivers to sign an informed consent form. The research was approved by the Ethics Committees of the Department of Psychology at the Università Cattolica del Sacro Cuore (Milan) and Politecnico di Milano.

Data analysis

The workshops were audio-recorded and transcribed verbatim in order to minimise the risk of data loss. ${ }^{66}$ Since this study aimed to investigate the adoption of co-production by looking at the behaviour 
of family caregivers,${ }^{67}$ the use of an inductive approach to analyse the data is suggested. ${ }^{57}$ We coded the transcripts using NVivo, and the data were analysed by referring to a preliminary coding guideline. However, this guideline was used in a flexible way; it was integrated/modified and enriched during the analysis as new insights from the data emerged requiring new codes. Every time a new code emerged, we reviewed the transcripts to check for any inconsistencies.

The preliminary coding guideline was based on the spectrum of citizen engagement proposed by Loeffler and $\operatorname{Martin}^{47}$, since we wanted to deepen the understanding about whether and how family caregivers co-produce by distinguishing it from other types of engagement.

Among the several frameworks suggested in the current literature, we decided to adopt Loeffler and Martin's ${ }^{47}$ approach, since it allowed us to study the succession of the different levels of engagement and how co-production was facilitated through the methods the facilitators used to conduct the workshops.

In the preliminary coding guideline, the second-order themes coincided with the three levels of engagement suggested by the model, i.e. consultation, participation and co-production. ${ }^{47}$ Then, each theme was categorised and assigned codes (Table 3) using a replicable and transparent process.

The first level, the information level, cannot be considered to be a type of public engagement since the information only flows in one direction. At this level, providers give information to users, but they do not listen to the users' suggestions or preferences.

The consultation level occupies the bottom of the public engagement ladder; it entails a two-way exchange between providers and users, but it only allows users to make a minimal contribution to the process. This level allows users to state their preferences regarding a specific set of options. Based on a decision made or a service offered by the providers, the users are asked to express their preferences, which the providers may partially or completely consider. ${ }^{47}$ In our case, during the first part of workshops 1, 2 and 3, the facilitators asked the users questions in order to investigate their needs and identify the difficulties they encountered in being family caregivers. Based on these findings, we identified three categories for the consultation theme: facilitators' requests, providers' requests and caregivers' feedback.

At the participation level, users and providers are involved in a public dialogue and exchange that ensures a higher level of contribution than is possible at the consultation level. ${ }^{47}$ This gives them much more space to express their preferences and opinions and to debate and discuss them with providers. ${ }^{68}$ Thus, the process is a sequence of different views in which people agree or disagree with each other. In our case, the caregivers, providers and facilitators discussed a specific service solution. 
During the discussion, they agreed or disagreed with the topic being discussed, sharing their personal views about it. ${ }^{47}$ Thus, we identified two categories for the participation theme. The first category includes all the actors' views that agree with the other actors' statements. The second category includes all the conflicting views that disagree with the other actors' statements. Based on these findings, we identified the following categories for the participation theme: facilitators agree with caregivers, providers agree with caregivers, caregivers agree with other caregivers, caregivers agree with facilitators, caregivers agree with providers, caregivers disagree with other caregivers, caregivers disagree with facilitators and caregivers disagree with providers. The other possible categories (e.g. facilitators disagree with caregivers) are not reported because they have any representative quotes.

The co-production level is placed at the top of the public engagement ladder. It differs from the participation level in that users make a substantial contribution to improving current services. Users collaborate closely with providers in the planning, design, delivery or assessment phases to improve the services and their outcomes. They are considered 'experts by experience', ${ }^{\text {(pp. 295) }}{ }^{2}$ and they do not need the support of the provider because they can leverage their own resources and effort. ${ }^{47}$ In our case, during the second part of workshops 1, 2 and 3, and throughout all of workshop 4, the participants were encouraged to identify a new service solution that would support them in caring for elders. While some of the participants suggested and prioritised possible interventions without explaining how to achieve them, others provided details about interventions and designed new possible service solutions. Thus, we identified two categories for the co-production theme: cocommissioning and co-design. In the first category, we included all the interventions suggested by the caregivers, facilitators and providers as relevant and urgent. In the second category, we included the explanations and details proposed by the different actors that delineate how to implement a new possible service solution. Based on these findings, we identified six categories for the co-production theme: co-commissioning by facilitators, co-commissioning by providers, co-commissioning by caregivers, co-design by facilitators, co-design by providers and co-design by caregivers.

Table 3 presents the prefigured codes scheme that links the second-order themes identified from the theory with the first-order categories ${ }^{69}$ During the analysis, this scheme was integrated/modified with emerging codes that could not fit with the a priori themes and categories. ${ }^{70}$

Table 3 Themes, categories and examples of the coding system

\begin{tabular}{c|c|c} 
Themes & Categories & Example of Categories and Codes \\
\hline Consultation & Facilitators' requests & Let us understand the positive and negative aspects [of being family caregivers] that you are \\
\cline { 2 - 3 }
\end{tabular}




\begin{tabular}{|c|c|c|}
\hline & Providers' requests & $\begin{array}{c}\text { In particular, [we would like] to understand your needs and which topic requires additional } \\
\text { information. }\end{array}$ \\
\hline & Caregivers' feedback & $\begin{array}{l}\text { - User 1: [..] Then, I have some issues transferring my mother from the wheelchair to the car. } \\
\text { - User 2: We have to think also about the assisted living facility, but it is too expensive. I earn } \\
600 € \text { per month. } \\
\text { - User 3: [My mother] cannot take care of herself anymore [... She can barely wash herself } \\
\text { and go to the toilet. }\end{array}$ \\
\hline \multirow{8}{*}{ Participation } & $\begin{array}{l}\text { Facilitators agree with } \\
\text { caregivers }\end{array}$ & I agree, $[\ldots]$ it seems a good idea. \\
\hline & $\begin{array}{l}\text { Providers agree with } \\
\text { caregivers }\end{array}$ & On this, I completely agree with you and I am very sorry for what happened. \\
\hline & $\begin{array}{l}\text { Caregivers agree with } \\
\text { other caregivers }\end{array}$ & As the madam did, I book an appointment with the geriatrician at home. \\
\hline & $\begin{array}{l}\text { Caregivers agree with } \\
\text { facilitators }\end{array}$ & I like your idea of being updated [about new services and regulations] \\
\hline & $\begin{array}{l}\text { Caregivers agree with } \\
\text { providers }\end{array}$ & Yes, it is not the social workers' fault! \\
\hline & $\begin{array}{l}\text { Caregivers disagree with } \\
\text { other caregivers }\end{array}$ & No, I don't' think [the disability allowance] should work as you have just proposed. \\
\hline & $\begin{array}{l}\text { Caregivers disagree with } \\
\text { facilitators }\end{array}$ & No! [internet] is useful! But it gives us too much information. \\
\hline & $\begin{array}{l}\text { Caregivers disagree with } \\
\text { providers }\end{array}$ & No! [the social workers] are not available in the local districts [ 36 hours a week]! \\
\hline \multirow{6}{*}{$\begin{array}{l}\text { Co- } \\
\text { production }\end{array}$} & $\begin{array}{l}\text { Co-commissioning by } \\
\text { facilitators }\end{array}$ & Indeed, the other obvious and undeniable need is the movement and circulation in the valley. \\
\hline & $\begin{array}{l}\text { Co-commissioning by } \\
\text { providers }\end{array}$ & Thus, a training session may be a solution! \\
\hline & $\begin{array}{l}\text { Co-commissioning by } \\
\text { caregivers }\end{array}$ & We need to have the possibility of contacting a person that knows everything! \\
\hline & Co-design by facilitators & $\begin{array}{l}\text { That is a good idea. Then, all the caregivers invest part of their time, skills and competences in the } \\
\text { project. [...]; for example, to overcome the issue of the movement along the valley, caregivers } \\
\text { can organise [with each other] for the movements. }\end{array}$ \\
\hline & Co-design by providers & $\begin{array}{l}\text { Within these practical training sessions, there may be a person that can explain to you exactly } \\
\text { why, when " doing this, you need to do this, etc." }\end{array}$ \\
\hline & Co-design by caregivers & $\begin{array}{l}\text { [It may be] a service that allows me to book a visit [for my dear one] via the internet or via a } \\
\text { phone call, which is much easier. }\end{array}$ \\
\hline
\end{tabular}

\section{Results}

This section is organised into two subsections. The first subsection describes the results from the coding process. The second subsection presents a deeper analysis at the co-production level.

\section{Coding analysis}

The coding analysis results reveal that the co-production level covers, on average, $15 \%$ of the content of the transcripts; the consultation and participation levels cover $27.2 \%$ and $2.2 \%$ of the content, 
respectively. During the analysis, we added two additional themes, contextualisation and envisioning, to explain the data in the transcripts.

The contextualisation theme includes information that describes the project (7\%), the health and social care services organisations (6\%) and personal or family life events or activities (31.18\%). We added this theme because the related contextual information did not fit any of the themes identified in the literature. This information does not support the workshop participants in designing new services or explain the needs of caregivers; moreover, it is not part of the decision-making processes.

The envisioning theme includes stimuli for incentivising users to deepen and enrich their previous statements or to think about new possible service solutions. These stimuli were suggested by the facilitators and the providers and, in a few cases, by some of the caregivers. This mechanism does not coincide with any phases of engagement. It differs from consultation, as the purpose of the facilitators or providers' requests is not to obtain caregivers' opinions but to encourage them to design new service solutions. Furthermore, it does not coincide with co-production, as the facilitators or providers are not exposing possible service solutions; rather, they are summarising what the users said. Thus, we decided to cluster the envisioning theme into a separate theme, even if it only covers, on average, $1.8 \%$ of all the content in the transcripts.

Table 4 presents a summary of the two new themes and the related categories with a specific example of codes and categories.

Table 4 Additional themes, categories and examples of the coding system

\begin{tabular}{|c|c|c|}
\hline Themes & Categories & Examples of the Categories and Codes \\
\hline \multirow{3}{*}{$\begin{array}{l}\text { Contextualisa } \\
\text { tion }\end{array}$} & $\begin{array}{c}\text { Project } \\
\text { information }\end{array}$ & $\begin{array}{l}\text { This service will be a pilot test, so we will need to collect, measure and assess data [arising from the project] } \\
\text { under different points of views. }\end{array}$ \\
\hline & $\begin{array}{l}\text { Services } \\
\text { information }\end{array}$ & $\begin{array}{l}\text { How does it work? The social workers' information desk is free of charge, so citizens interesting in a new } \\
\text { service should go there and ask for the new service to be activated. }\end{array}$ \\
\hline & $\begin{array}{l}\text { Personal } \\
\text { information }\end{array}$ & $\begin{array}{l}\text { My dad is } 88 \text {-years-old and he has been in this condition since undergoing an arduous surgery that was } \\
\text { necessary because he was dying due to an intestinal blockage. }\end{array}$ \\
\hline \multirow{3}{*}{ Envisioning } & $\begin{array}{l}\text { Envisioning by } \\
\text { facilitators }\end{array}$ & What can help you? What [are the services that] can give you some rest? \\
\hline & $\begin{array}{l}\text { Envisioning by } \\
\text { providers }\end{array}$ & $\begin{array}{c}\text { Sometimes, it happens that [the caring of elders] separates and breaks a family apart. What is your personal } \\
\text { experience of it? }\end{array}$ \\
\hline & $\begin{array}{l}\text { Envisioning by } \\
\text { caregivers }\end{array}$ & How many diapers [the healthcare service] do you receive each month? \\
\hline
\end{tabular}

Each workshop includes all the different phases of involvement (consultation, participation and coproduction) as well as information related to the caregivers and their life experience (contextualisation) and stimuli to enrich the discussion (envisioning). Thus, each workshop contains 
all the themes identified in the coding analysis. Workshop 4, which was completely dedicated to codesigning a new service, had the highest level of co-production. The other three workshops, in which only some of the time was dedicated to co-design activities, had a lower level of co-production. In all four workshops, the contextualisation theme had the highest percentage of text coverage, while the participation and envisioning themes had the lowest percentage of text coverage.

Caregivers do not contribute to co-production activities in the same way. There are relevant differences between users in terms of their contributions to these activities. In particular, caregivers with a higher level of text coverage for the co-production theme reported having less contextual information (contextualisation theme), and vice versa. (For more details about the analysis, see the information provided in the Appendix).

\section{Family caregivers and co-production}

To analyse how to facilitate the adoption of co-production, we investigated the parts of the texts that contain codes and categories related to the co-production theme. During the co-design process, caregivers provided brief and, in some cases, confusing statements. The actors usually interrupted one another, talked over or started a different discussion with their peers in the room while others were speaking. Thus, co-productive discussions were characterised by a set of short sentences in quick succession reported by several participants. The tone of voice of the participants was mediumhigh as they tried to intervene in other actors' discussions, without waiting their turn.

CG2: Thus, I... would like to say an important issue, at least for me, that the woman raised before. We should have the possibility for a small period of time to...

CG5: We need to take a break! Otherwise, we go crazy!

CG2: Right! A place where we can bring them for a week, a month.

CG5: It's sad to say, but psychologically...

CG1: Not an assisted living facility! Where you bring your dear one for the rest of his life. I mean that there should be an end!

CG5: Do not misunderstand?! We do not want to take our dear ones or her husband out! Psychologically, you need to take a break. We do not have a life any more. Especially in her situation! She manages to survive somehow, even if she has two people to take care of!

CG3: But she does not have them in her house?! I have [my husband] at home!

Each caregiver's intervention added some content to the final service solution. The content refers to either a new caregiver idea or a previously mentioned one. The co-producing process is often interrupted by topics or issues related to the personal life of the caregivers or by arguments between them. This shift in content is confirmed by the coding analysis (see the Appendix for more information). The codes related to co-production were interrupted by phrases or statements related to 
other themes, such as contextualisation, consultation and participation. Thus, a discussion about a possible service solution was usually interrupted by digressions that do not add any details to the service solution, losing the train of thought.

CG1: With the bedpan! I have already arranged everything and I have just bought a new bedpan.

CG4: If it is possible, I will prefer to participate [in training activities for caregivers]. Otherwise, I can learn with...

Provider: Listening to you, I think it may be useful to organise a set of training sessions, to give them a more concrete name.

CG1: Indeed, at the beginning [of the home care service] I was always looking at the women that come to our home for the caring activities.

Provider: Did you do it to check what and how they were doing the caring activities?

CG1: Yes!

CG4: I taught them how to care for [my dear one] so they were able to do the things as I was doing, but they sent me away!

Provider: Thus, does a set of lessons on caring topics help you?

To encourage the co-production process and prevent interruptions or digressions, the facilitators and, in a few cases, the providers, encouraged some actions. First, they asked the participants to be quiet and respect each other during the discussions when things started to become too noisy and confusing. Second, they interrupted the off-topic discussion asking the participants to refocus on the co-design activities. Third, they introduced new possible service ideas based on the ones that arose in the previous workshops or based on the recurrent issues discussed during the workshops. Finally, they summarised the main topic and issues that were discussed to clarify the group's ideas. Once they organised the participants' thoughts, they asked them to reflect on the issues or ideas that arose from the discussion, encouraging the co-production process.

Facilitator: We should speak one at a time! Sorry $[\ldots]$

Facilitator: Do you think that the organisation of a priest's visits for fragile elders living at home is a good idea? $[\ldots]$

Facilitator: We did two other workshops before this one [...]. During the workshops, several services were proposed. One was the creation of a brochure with all relevant information [about the care of elders] [...] or a website or a toll-free-number. These are included in the first set of service proposals. What do you think of them? [...]

Facilitator: Going back to the topic that the woman was presenting: breaks, periods off in which others [professionals] substitute for you in caring for elders. Okay? Do you have other ideas?

Both the introduction of new service proposals and the stimuli to reflect on previously mentioned ideas often led the caregivers to refocus on the co-production process, and it facilitated the co-design of new services. However, these last two actions did not always work as hoped, and the caregivers 
continued to digress by discussing personal topics or arguing about specific issues not related to the co-design of new services (to deepen the analysis, see the information provided in the Appendix). Consequently, both the facilitators and the providers interrupted the caregivers' discussion several times trying to help them refocus on the co-production process.

\section{Discussion}

The present study's findings contribute to the existing debate about co-production with vulnerable actors by reflecting on the stages needed to achieve co-production and the conductive methods to promote it.

\section{The stages to achieve co-production}

Although the existing literature challenges the fact that vulnerable actors are able and willing to coproduce, ${ }^{18}$ the present research proved that the caregivers could, at least partially, translate their problems into concrete actions or proposed services. The high level of stress and burden of caregivers made the co-production process more challenging than usual because the caregivers were partially unable or unwilling to critically analyse their problems and design new service solutions.

In line with this consideration, our findings suggest that the adoption of co-production by vulnerable actors may occur in conjunction with other forms of engagement; thus, the facilitators have the complex role of shifting the participants' focus toward co-production activities. This finding contributes to disclosing the ostensible inconsistency in the literature about the concurrency of the levels of engagement (see Mangai and de Vries vs Loeffler and Martin's frameworks). At least with vulnerable actors, it seems that the different forms of engagement are not mutually exclusive; they may co-exist within the same discussion.

In particular, we confirmed the concurrency of the three forms of engagement suggested by Loeffler and Martin's framework (i.e. consultation, participation and co-production). ${ }^{47}$ In our case, family caregivers often shifted the focus of the conversation and started explaining (i.e. consultation) or discussing the existing services or issues they face in their caregiving routine with other participants (i.e. participation) instead of co-producing new service solutions.

Moreover, we added an additional stage, i.e. contextualisation, that cannot be considered an actual level of engagement. Indeed, it reports information that is not useful for co-designing the service as it is strictly related to the caregivers' personal experience. However, this step is fundamental if vulnerable actors have to move from a passive role to an active one. Especially at the beginning of the workshops, the caregivers exploited the time to introduce themselves by sharing very personal information related to their daily life and experiences. Even if no one asked them to speak about their personal life, they could not stop themselves from doing so. Thus, the 'ice-breaker' activities 
suggested by Dietrich et al. turned out to be fundamental for involving caregivers in the discussion. ${ }^{53}$ The caregivers needed a shoulder to cry on to unload their stress before starting to focus on the facilitators' requests. Thus, the contextualisation stage can be considered to be a useful step for increasing cohesiveness within the group and setting the stage for launching the co-production process. $^{48}$

Finally, we introduced the envisioning theme, which highlights the importance of directing the participants during the discussion. Sometimes the caregivers tended to digress, losing the focus of the discussion. Other times, the participants did not respect their turn; they interrupted other participants while they were speaking. Moreover, they constantly moved from one topic to another without properly reflecting on and investigating it. In all these cases, it is important to break into the discussion to ensure that the group discussion developed properly over time. As confirmed by our findings, the facilitators have the duty to ask participants to respect the turn-taking process, focus on the topics of discussion by clarifying their boundaries and incentivise them to concentrate on the previously mentioned topics. In confirmation of these findings, the recent co-design literature suggested that facilitators should keep in mind basic principles, i.e. focus, boundaries and rumination, that support them throughout the co-design process. ${ }^{71}$

\section{The complex role of facilitators}

However, co-production is not easy to achieve with vulnerable actors. There are several unsuccessful examples of co-production with vulnerable actors that arise from conflicts, misunderstandings and unwillingness of and between participants. ${ }^{72-74}$ Thus, the facilitators play a crucial and challenging role in encouraging the successful adoption of co-production. ${ }^{75}$

Based on our empirical findings, we identified at least two strategies that may help facilitators and providers enhance the actualisation and articulation of service ideas. ${ }^{76}$ First, they can summarise the issues related to the services that arise during the workshop and facilitate a new discussion on those topics. In this case, the facilitators guide participants through the co-production process, making their contributions concreate and clear. The facilitators only organise, interpret and synthesise the emerging issues and ideas without adding their personal contribution. ${ }^{64}$ Second, they can interrupt the vulnerable actors' digressions or off-topic discussions by providing possible examples of service solutions to incentivise them to participate in the co-production activities. In this case, facilitators play an active role: they do not simply guide the process, they initiate the co-production. They suggest new service proposals to trigger the group discussion with innovative ideas that arise from their personal experience and knowledge, helping the participants think 'out-of-the-box' (Selloni, ${ }^{64}$ p. 172) 
As proven by our analysis, these two strategies are not mutually exclusive; facilitators may have to frequently implement them during the discussion with vulnerable actors.

Interestingly, these strategies confirm, at least partially, the ones suggested by the co-design literature. In line with the co-design framework of Pedersen, in the first strategy, the facilitators seem to (re)frame the findings that have just arisen from the discussion (i.e. negotiation stage) by clarifying the issues to discuss. ${ }^{54}$ The second strategy seems to replicate the succession of the Collaborative Design Framework stages of Meroni et al. ${ }^{55}$ In particular, to facilitate co-production, the facilitators incentivise participants to shift from a topic-driven discussion to a concept-driven discussion, from topics related to the participants' experience to topics on possible service ideas. ${ }^{55}$

However, there is still relatively few guidelines about how the participants and the facilitators should interact to encourage the co-production process. ${ }^{45}$ Facilitators should find the right balance between listening to participants as they spontaneously express their needs and priorities and, by being empathetic, lead them to engage in a better focused and productive discussion. Thus, a deep knowledge about human interaction dynamics and the psychological process of creativity elicitation would best equip facilitators for conducting co-productive workshops. Clarifying the types of interactions that characterise co-production processes will support facilitators and providers in implementing co-production, thereby preventing pitfalls and decreasing the possibility that it will not be adopted. ${ }^{77}$

\section{Practical implications}

To reflect on these findings, we suggest some practical tips that may help researchers and practitioners achieve co-production with vulnerable actors.

At the beginning of the co-production process, the facilitators should organise ice-breaker activities to encourage vulnerable actors to share information about their personal lives. Although this stage (i.e. contextualisation) requires time and may lengthen the duration of the workshop, it is fundamental to making the participants engage in and feel confident about interacting with the rest of the group. ${ }^{53}$ Then, throughout the process, the facilitators should incentivise the group members to focus on the discussion by clarifying the boundaries and concentrating on the relevant topic before changing it (i.e. envisioning).

However, these tips may not be sufficient to achieve co-production. To accomplish that, we suggest that the facilitators adopt at least two possible strategies. First, they have to summarise the discussed topics by clarifying the focus of the discussion. Second, they should encourage participants to change the content of the discussion, shifting from a topic-driven discussion to a concept-driven discussion. 
Last, but not least, the facilitators should balance the power between the users and the providers; this is the main characteristic that distinguishes co-production from the other types of engagement. ${ }^{1,2,7,16}$ Toward that end, they should prevent providers (and other influencing actors) from interrupting the discussion and imposing their opinions upon others. They should also encourage vulnerable actors to express their personal opinions and discuss them with others by making them feeling useful.

\section{Conclusion}

Individual factors influencing citizens' co-production have garnered a significant amount of attention in the last 20 years. ${ }^{18}$ However, to the best of our knowledge, there is still a debate on the possibility of involving vulnerable users in co-production activities. ${ }^{7}$

Thus, we investigated how co-production is facilitated in the co-design of new public services by involving family caregivers living in a remote and rural area in northern Italy (Vallecomonica). Identifying necessary public services for family caregivers using a co-production approach allows researchers to obtain relevant findings. Family caregivers are able to participate in co-production activities despite their vulnerable condition. However, involvement is more challenging for family caregivers than it is for other public service users, and it requires the effort and support of facilitators to move from the traditional forms of engagement towards co-production. Indeed, we proved that, at least with vulnerable actors, the different forms of engagement occur concurrently. To achieve the co-production level, vulnerable actors usually have to pass through the more traditional levels of engagement (i.e. consultation, participation).

Consequently, we suggest two possible strategies that support facilitators in encouraging coproduction. In the first strategy, the facilitators summarise the discussed topics to organise existing findings and guide the discussion. In the second strategy, the facilitators initiate the co-production process by suggesting new possible services solutions that participants have not mentioned yet. However, more research is needed, as these strategies are just an initial contribution to exploit how to design and incentivise the co-production process with vulnerable actors. Thus, we proved that the co-design literature could be a useful starting point for investigating this debated issue.

In conclusion, it is possible to involve vulnerable users, such as family caregivers, in co-production activities. However, the research findings stress that the facilitators must exert more effort with this group of users than they do with other actors to facilitate the co-production process.

\section{Limitations and further investigations}

This research study has some limitations linked to the specificity of the context of the analysis. ${ }^{78} \mathrm{We}$ investigated the adoption of co-production by vulnerable actors by looking at a single case that focused on a specific type of vulnerable users (family caregivers in the Italian remote community of 
Vallecamonica) and one out of four phases of user involvement (i.e. co-design). Thus, the selection of other types of vulnerable actors in different phases of involvement should be further investigated to enrich and confirm the present research study's findings.

Furthermore, we decided to organize the workshops by referring questions mainly to caregivers to prevent possible power imbalance. Indeed, the vulnerability of family caregivers and the institutional role of service providers could have influenced and limited the contributions of caregivers. As predictable, providers contributed to the discussion anyway. However, future studies should investigate how to balance the power of providers in co-production with vulnerable actors by ensuring their active contribution in the workshops.

Finally, future studies should investigate the link between the interactions among actors and coproduction to support the ability of facilitators and providers to actually implement the process. Understanding the interactions that characterise co-production will also prevent the pitfalls that can be encountered in the process or the ineffective involvement of the users. ${ }^{77}$

\section{Acknowledgements}

This research is part of the Place4Carers project funded by Fondazione Cariplo.

\section{Conflicts of interest}

All the authors declare that they have no conflict of interest. 


\section{Bibliography}

1. Brandsen T, Steen T, Verschuere B. Co-Production and Co-Creation. Routledge. Abingdon: Routledge, 2018.

2. Nabatchi T, Sancino A, Sicilia M. Varieties of Participation in Public Services:

The Who, When, and What of Coproduction. Public Adm Rev 2017; 77: 766-776.

3. Grönroos C. Reforming public services: does service logic have anything to offer? Public Manag Rev 2019; 21: 775-788.

4. Loeffler E, Bovaird T. From participation to co-production: Widening and deepening the contributions of citizens to public services and outcomes. Palgrave Handb Public Adm Manag Eur 2017; 403-423.

5. Norris JM, White DE, Nowell L, et al. How do stakeholders from multiple hierarchical levels of a large provincial health system define engagement? A qualitative study. Implement Sci 2017; 12: 1-13.

6. Holmes B. Citizens 'engagement in policymaking and the design of public services, www.aph.gov.au/About_Parliament/Parliamentary_Departments/Parliamentary_\%0ALibrary /pubs/rp/rp1112/12rp01 (2011).

7. Brandsen T, Honingh M. Distinguishing Different Types of Coproduction: A Conceptual Analysis Based on the Classical Definitions. Public Adm Rev 2016; 76: 427-435.

8. Sorrentino M, Sicilia M, Howlett M. Understanding co-production as a new public governance tool. Policy Soc 2018; 37: 277-293.

9. Pestoff V. Citizens and co-production of welfare services. Childcare in eight European countries. Public Manag Rev 2006; 8: 503-519.

10. Löffler E, Parrado S, Bovaird T, et al. 'If you want to go fast, walk alone. If you want to go far, walk together' Citizens and the co-production of public services. Paris, www.5qualiconference.eu. (2008, accessed 14 May 2020).

11. Ostrom E. Crossing the great divide: Coproduction, synergy, and development. World Dev 1996; 24: 1073-1087.

12. Loeffler E, Bovaird T. User and Community Co-Production of Public Services: What Does the Evidence Tell Us? Int J Public Adm 2016; 39: 1006-1019.

13. Pestoff V. Collective Action and the Sustainability of Co-Production. Public Manag Rev 2014; 16: 383-401.

14. Fledderus J, Honingh M. Why people co-produce within activation services: the necessity of motivation and trust - an investigation of selection biases in a municipal activation programme in the Netherlands. Int Rev Adm Sci 2016; 82: 69-87.

15. Farooqi SA. Co-production: what makes co-production work? Evidence from Pakistan. Int J Public Sect Manag 2016; 29: 381-395.

16. Bovaird T. Beyond engagement and participation: User and community coproduction of public services. Public Adm Rev 2007; 67: 846-860.

17. Park S. Beyond patient-centred care: a conceptual framework of co-production mechanisms with vulnerable groups in health and social service settings. Public Manag Rev 2020; 22: $452-474$. 
18. Alonso JM, Andrews R, Clifton J, et al. Factors influencing citizens' co-production of environmental outcomes: a multi-level analysis. Public Manag Rev 2019; 21: 1620-1645.

19. Bovaird T, Van Ryzin GG, Loeffler E, et al. Activating citizens to participate in collective co-production of public services. J Soc Policy 2015; 44: 1-23.

20. Ballantyne D, Richard JV. Introducing a Dialogical Orientation to the Service-Dominant Logic of Marketing. In: Lusch RF, Stephen LV (eds) The Service-Dominant Logic of Marketing: Dialog, Debate, and Directions. New York: Routledge, 2006, pp. 224-235.

21. Kaskie B, Imhof S, Cavanaugh J, et al. Civic Engagement as a Retirement Role for Aging Americans, https://academic.oup.com/gerontologist/article-abstract/48/3/368/553846 (2008, accessed 12 May 2020).

22. Osborne SP, Radnor Z, Strokosch K. Co-Production and the Co-Creation of Value in Public Services: A suitable case for treatment? Public Manag Rev 2016; 18: 639-653.

23. Evils S. The Dark Side of Co-Creation and Co-Production. In: Brandsen T, Steen T, Verschuere B (eds) Co-Production and Co-Creation: Engaging Citizens in Public Services. New York: Routledge, 2018.

24. Parrado S, van Ryzin GG, Bovaird T, et al. Correlates of Co-production: Evidence From a Five-Nation Survey of Citizens. Int Public Manag J 2013; 16: 85-112.

25. Sicilia M, Sancino A, Nabatchi T, et al. Facilitating co-production in public services: management implications from a systematic literature review. Public Money Manag 2019; 39: $233-240$.

26. Boudioni M, Mclaren S, Lister G. Patient empowerment: Its implementation and systems within hospitals in England and Greece. DOI: 10.1177/0951484817752628.

27. International Federation of Red Cross. What is vulnerability?, https://www.ifrc.org/en/whatwe-do/disaster-management/about-disasters/what-is-a-disaster/what-is-vulnerability/ (2018, accessed 12 May 2020).

28. Morelli N, Barello S, Mayan M, et al. Supporting family caregiver engagement in the care of old persons living in hard to reach communities: A scoping review. Heal Soc Care Community 2019; 27: 1363-1374.

29. Waller P. Co-production and co-creation in public services: Resolving confusion and contradictions. Int J Electron Gov Res 2017; 13: 1-17.

30. van Eijk CJA, Steen TPS. Why People Co-Produce: Analysing citizens' perceptions on coplanning engagement in health care services. Public Manag Rev 2014; 16: 358-382.

31. Voorberg WH, Bekkers VJJM, Tummers LG. A Systematic Review of Co-Creation and CoProduction: Embarking on the social innovation journey. Public Manag Rev 2015; 17: 13331357.

32. Alford J. The Multiple Facets of Co-Production: Building on the work of Elinor Ostrom. Public Manag Rev 2014; 16: 299-316.

33. Sicilia M, Guarini E, Sancino A, et al. Public services management and co-production in multi-level governance settings. Int Rev Adm Sci 2016; 82: 8-27.

34. van Kleef D, van Eijk C. In or Out: Developing a Categorization of Different Types of CoProduction by Using the Critical Case of Dutch Food Safety Services. Int J Public Adm 2016; 39: 1044-1055. 
35. Palumbo R, Vezzosi S, Picciolli P, et al. Fostering organizational change through coproduction. Insights from an Italian experience. Int Rev Public Nonprofit Mark 2018; 15 : 371-391.

36. Luu TT, Rowley C, Dinh KC. Enhancing the effect of frontline public employees' individual ambidexterity on customer value co-creation. J Bus Ind Mark 2018; 33: 506-522.

37. Tuurnas SP, Stenvall J, Rannisto PH, et al. Coordinating co-production in complex network settings. Eur J Soc Work 2015; 18: 370-382.

38. Lindsay C, Pearson S, Batty E, et al. Street-level practice and the co-production of third sector-led employability services. 2018. Epub ahead of print 2018. DOI: 10.1332/030557317X15120417452025.

39. Alford J. Co-Production, Interdependence and Publicness: Extending public servicedominant logic. Public Manag Rev 2016; 18: 673-691.

40. Bovaird T, Loeffler E. From Engagement to Co-production: The Contribution of Users and Communities to Outcomes and Public Value. Voluntas 2012; 23: 1119-1138.

41. Brandsen T, Honingh M. Definitions of Co-Production and Co-Creation. In: Brandsen T, Steen TPS, Verschuere B (eds) Co-Production and Co-Creation: Engaging Citizens in Public Services. New York: Routledge, 2018.

42. Park S. Beyond patient-centred care: a conceptual framework of co-production mechanisms with vulnerable groups in health and social service settings. Public Manag Rev 2020; 22: $452-474$.

43. Whitaker GP. Coproduction: Citizen Participation in Service Delivery. Public Adm Rev 1980; 40: 240.

44. Mangai MS, De Vries MS. Co-production as deep engagement: Improving and sustaining access to clean water in Ghana and Nigeria. Int J Public Sect Manag 2018; 31: 81-96.

45. Stewart J. The Dilemmas of Engagement. Canberra: ANU E Press, 2009.

46. Arnstein SR. A Ladder Of Citizen Participation. J Am Plan Assoc 1969; 35: 216-224.

47. Loeffler E, Martin S. Public management and governance. In: Bovaird T, Loeffler E (eds) Citizen engagement. London: Routledge, 2015.

48. Trischler J, Pervan SJ, Kelly SJ, et al. The Value of Codesign: The Effect of Customer Involvement in Service Design Teams. J Serv Res 2018; 21: 75-100.

49. Fledderus J. Does User Co-Production of Public Service Delivery Increase Satisfaction and Trust? Evidence From a Vignette Experiment. Int J Public Adm 2015; 38: 642-653.

50. Liabo K, Boddy K, Bortoli S, et al. Public involvement in health research: What does 'good' look like in practice? Res Involv Engagem 2020; 6: 1-12.

51. Bovaird T, Flemig S, Loeffler E, et al. How far have we come with co-production-and what's next? Public Money Manag 2019; 39: 229-232.

52. Sanders E, Stappers PJ. Co-creation and the new landscapes of design. Co-Design 2008; 4: $5-18$.

53. Dietrich T, Trischler J, Schuster L, et al. Co-designing services with vulnerable consumers. $J$ Serv Theory Pract 2017; 27: 663-688. 
54. Pedersen S. Staging negotiation spaces: A co-design framework. Des Stud 2020; 68: 58-81.

55. Meroni A, Selloni D, Rossi M. Massive Codesign. A Proposal for a Collaborative Design Framework. Milan: FrancoAngeli, http://ojs.francoangeli.it/_omp/index.php/oa/catalog/book/303\%0Ahttp://files/359/Meroni et al. - Massive Codesign. A Proposal for a Collaborative D.pdf\%0Ahttp://files/358/303.html (2018).

56. Yin R. Case Study Research: Design and Methods. Second Edi. Thousand Oaks: SAGE Publications, 1994.

57. Yin RK. The Case Study as a Serious Research Strategy. Sci Commun 1981; 3: 97-114.

58. Gibbert M, Ruigrok W, Wicki B. What passes as a rigorous case study? Strateg Manag J 2008; 29: 1465-1474.

59. Graffigna G, Barello S, Morelli N, et al. PLACE4CARERS: A mixed-method study protocol for engaging family caregivers in meaningful actions for sucessful aging in place. BMJ Open.

60. Eisenhardt KM. Building Theories from Case Study Research Published by : Academy of Management Stable URL : http://www.jstor.org/stable/258557 Linked references are available on JSTOR for this article : Building Theories from Case Study Research. 2016; 14: $532-550$.

61. Pettigrew AM. Longitudinal Field Research on Change: Theory and Practice. Organ Sci 1990; 1: 267-292.

62. Náthalie Rodrigues Pinto FF, Joan Barham E, Pereira Del Prette AZ. Interpersonal Conflicts Among Family Caregivers of the Elderly: The Importance of Social Skills. Paidéia 2016; 26: 161-170.

63. De Vugt ME, Stevens F, Aalten P, et al. Do caregiver management strategies influence patient behaviour in dementia? Int J Geriatr Psychiatry 2004; 19: 85-92.

64. Selloni D. Codesign for the Public Interest. 2017. Epub ahead of print 2017. DOI: 10.1007/978-3-319-53243-1_11.

65. Farr M. Power dynamics and collaborative mechanisms in co-production and co-design processes. Crit Soc Policy 2018; 38: 623-644.

66. Halcomb EJ, Davidson PM. Is verbatim transcription of interview data always necessary? Appl Nurs Res 2006; 19: 38-42.

67. Thomas DR. A General Inductive Approach for Analyzing Qualitative Evaluation Data. Am J Eval 2006; 27: 237-246.

68. Fainstein SS. New Directions in Planning Theory. Urban Aff Rev 2000; 35: 451-478.

69. Elliott V. Thinking about the coding process in qualitative data analysis. Qual Rep 2018; 23: 2850-2861.

70. Lewis S. Qualitative Inquiry and Research Design: Choosing Among Five Approaches. Second Edi. Thousand Oaks, CA: SAGE Publications, 2007. Epub ahead of print 2007. DOI: $10.1177 / 1524839915580941$.

71. Trapani P. Designing Co-design: Addressing Five Critical Areas to Increase the Experience of Participants and Facilitator in a Co-design Session. In: Rau PP (ed) 11th International Conference, CCD 2019 Held as Part of the 21st HCI International Conference, HCII 2019. 
Orlando, FL, USA: Springer US, 2019, pp. 79-93.

72. Williams BN, Kang SC, Johnson J. (Co)-Contamination as the Dark Side of Co-Production: Public value failures in co-production processes. Public Manag Rev 2016; 18: 692-717.

73. Crompton A. Inside co-production: Stakeholder meaning and situated practice. Soc Policy Adm 2019; 53: 219-232.

74. Rantamäki NJ. Co-Production in the Context of Finnish Social Services and Health Care: A Challenge and a Possibility for a New Kind of Democracy. Voluntas 2017; 28: 248-264.

75. Mistry J, Berardi A, Bignante E, et al. Between a rock and a hard place: Ethical dilemmas of local community facilitators doing participatory research projects. Geoforum 2015; 61: 27 35 .

76. Kaehne A. Sharing a vision. Do participants in integrated care programmes have the same goals and objectives? Heal Serv Manag Res. Epub ahead of print 2019. DOI: $10.1177 / 0951484819871136$.

77. Dudau A, Glennon R, Verschuere B. Following the yellow brick road? (Dis)enchantment with co-design, co-production and value co-creation in public services. Public Manag Rev 2019; 21: 1577-1594.

78. Von Thiele Schwarz U. Co-care: Producing better health outcome through interactions between patients, Care providers and information and communication technology. Heal Serv Manag Res 2016; 29: 10-15. 